\title{
URÉIA EM COBERTURA E VIA FOLIAR EM FEIJOEIRO
}

\author{
Claudinei de Almeida'; Marco Antonio Camillo de Carvalho ${ }^{2,5}$; Orivaldo Arf ${ }^{3}$; Marco Eustáquio \\ de Sá3*; Salatiér Buzetti ${ }^{4}$ \\ ${ }^{1}$ Pós-Graduando do Depto. de Fitotecnia e Economia e Sociologia Rural - FEIS/UNESP. \\ ${ }_{3}^{2}$ Pós-Graduando do Depto. de Fitotecnia - FCAV-UNESP/Jaboticabal. \\ ${ }^{3}$ Depto. de Fitotecnia e Economia e Sociologia Rural - FEIS/UNESP, C.P. 31 - CEP: 15385-000 - Ilha Solteira, SP. \\ ${ }^{4}$ Depto. de Ciência do Solo e Engenharia Rural - FEIS/UNESP. \\ ${ }^{5}$ Bolsista FAPESP. \\ *Autor correspondente<mesa@agr.feis.unesp.br>
}

RESUMO: O presente trabalho foi desenvolvido com o objetivo de verificar a influência de diferentes concentrações de uréia $\left(0,40,60,80,100\right.$ e $\left.120 \mathrm{~g} \mathrm{~kg}^{-1}\right)$ em solução, para fornecimento de $\mathrm{N}$ via foliar, em diferentes horários (08h, 16h e 20h), na presença e ausência de adubação nitrogenada em cobertura (via solo). O solo do local do ensaio é do tipo Latossolo Vermelho-Escuro álico. O delineamento experimental seguiu o esquema fatorial $6 \times 3 \times 2$, com quatro repetições. A semeadura foi realizada mecanicamente no dia 24.06.1996, utilizando-se o cultivar IAC Carioca, conduzido em regime de irrigação. Aplicaram-se $200 \mathrm{~L} \mathrm{ha}^{-1}$ de calda, em cada pulverização com uréia. A adubação nitrogenada em cobertura foi realizada aos 32 dias após a emergência (dae), aplicando-se $40 \mathrm{~kg} \mathrm{ha}^{-1}$ de $\mathrm{N}$. Foram realizadas as seguintes avaliações: teor de agua e grau de fitotoxicidade nas folhas, número de dias para o florescimento pleno, matéria seca de plantas, teor de $\mathrm{N}$ total em folhas, número de vagens/planta, número de grãos/vagem, peso médio de 100 grãos e rendimento de grãos. A adubação nitrogenada em cobertura, aumentou a produtividade, o mesmo não ocorrendo com a adubação foliar. É importante a época de aplicação e a concentração da uréia foliar, devido a fitotoxicidade.

Palavras-chave: Phaseolus vulgaris, feijão, nitrogênio, adubação foliar

\section{FOLIAR AND SURFACE DRESSING OF UREA FOR THE COMMON BEAN CROP}

\begin{abstract}
The objective was to determine common bean response to different urea concentrations $(0,40$, $60,80,100$, and $\left.120 \mathrm{~g} \mathrm{~kg}^{-1}\right)$. N was supplied through leaves at different hours of application (8:00 AM, 04:00 $\mathrm{PM}$, and 08:00 PM), in either the presence or the absence of $\mathrm{N}$ (urea) soil surface dressing at the rate of $40 \mathrm{~kg} \mathrm{ha}^{-1} \mathrm{~N}$. The soil used was a clayey Typic Haplustox. The experimental design consisted of randomized blocks in a factorial scheme $5 \times 3$ with five urea rates and three times of application, with four replicates. Plant characteristics and degree of fitotoxicity were measured. It is concluded that $\mathrm{N}$ applied to the soil increased grain yield. $\mathrm{N}$ applied to leaves did not affect the agronomic characteristics nor bean yield.

Key words: Phaseolus vulgaris, beans, nitrogen, foliar fertilization
\end{abstract}

\section{INTRODUÇÃO}

O feijoeiro é uma planta de ciclo curto exigente em nutrientes, devido ao pequeno e pouco profundo sistema radicular. Por isso, é fundamental que os nutrientes sejam colocados à disposição da planta em quantidades, tempo e locais adequados.

A aplicação de $\mathrm{N}$ mineral nos solos tropicais pode resultar as vezes, em baixa freqüência de resposta pela cultura do feijão (Franco, 1977; Vieira, 1998). O aproveitamento do nitrogênio usado no adubo é normalmente inferior a $50 \%$, podendo em solos arenosos, atingir entre 5 a $10 \%$ (Duque et al., 1985), devido a grandes perdas por lixiviação ou desnitrificação (Gamboa, et al., 1971; Osiname et al., 1983). Conforme Rosolem (1987), tem sido obtido respostas do feijoeiro ao nitrogênio aplicado, de maneira generalizada no Brasil, embora a freqüência e a amplitude de resposta varia de região para região, e ainda dentro da mesma região em função do clima e das condições fitossanitárias da cultura. Rosolem (1996) citando Ambrossano et al. (1995) ${ }^{1}$, no Estado de São Paulo consideram-se duas classes de probabilidade de resposta ao nitrogênio: a alta que envolveria culturas irrigadas, solos arenosos, cultivos após gramíneas, solo compactado; e baixa que envolveria cultivo após leguminosas, solos em pousio por pelo menos dois anos e solos que recebem adubação orgânica freqüente.

Estudos envolvendo doses e épocas de aplicação de $\mathrm{N}$ via foliar, são extremamente importantes, pois essa prática pode trazer problemas ao desenvolvimento da planta em caso de fitotoxicidade causada pelo fertilizante nitrogenado. Segundo Rosolem \& Boaretto (1989), a aplicação de quantidades consideráveis de nitrogênio via foliar pode esbarrar no problema de ocorrência de

'AMBROSANO, E.J.; WUTKE, E.B.; BULISANI, E.A.; CANTARELLA, H. (Instituto Agronômico, Campinas). Comunicação pessoal, 1995. 
fitotoxidez, que poderá ser minimizado com a escolha da fonte do nutriente, do bico e do volume de calda, assim como o horário de aplicação.

Bulisani et al. (1973) verificaram que tanto a adubação mineral incorporada ao solo, quanto a adubação foliar, independentemente do número de aplicações, não influenciaram nos teores de nutrientes nas folhas. Observaram também, que fica plenamente justificado 0 prosseguimento dos estudos sobre o assunto, devido à facilidade de aplicação e custo relativamente baixo, mormente se as pulverizações com fertilizante foliar forem associadas a defensivos, e tendo em conta como promissor o aumento alcançado na produção do ensaio de $26 \%$, em relação à testemunha.

O presente trabalho teve como objetivos avaliar na cultura de feijão "de inverno", os efeitos da aplicação foliar do nitrogênio, bem como as possíveis interações dessa prática com a adubação nitrogenada em cobertura, via solo, e adequar a melhor concentração de calda ao horário de aplicação.

\section{MATERIAL E MÉTODOS}

O experimento foi desenvolvido em área experimental pertencente à Faculdade de Engenharia de Ilha Solteira - UNESP, localizada no município de Selvíria (MS), apresentando coordenadas geográficas de $51^{\circ} 22$ 'de longitude Oeste e $20^{\circ} 22^{\prime}$ de latitude Sul e altitude de 335 metros. O solo do local é Latossolo Vermelho-Escuro álico, textura argilosa. A precipitação média anual de $1.370 \mathrm{~mm}$, temperatura média anual de $23,5^{\circ} \mathrm{C}$ e umidade relativa do ar entre 70 a $80 \%$ (média anual). As condições de temperatura e umidade relativa do ar, na época do cultivo constam na TABELA 1.

As características químicas do solo foram determinadas antes da instalação do ensaio, seguindo metodologia proposta por Raij \& Quaggio (1983), apresentando os seguintes valores: 6,3 de $\mathrm{pH}$ em $\mathrm{CaCl}_{2}$; $34,0 \mathrm{~g} \mathrm{dm}^{-3}$ de matéria orgânica; $25 \mathrm{mg} \mathrm{dm}^{-3}$ de P; 2,2; 39,$0 ; 28,0 ; 16,0$ e $0 \mathrm{mmol}_{\mathrm{c}} \mathrm{dm}^{-3}$ respectivamente de $\mathrm{K}, \mathrm{Ca}$, $\mathrm{Mg}, \mathrm{H}+\mathrm{Al}$ e Al, e $81 \%$ de saturação por bases (V). O preparo do solo foi realizado por meio de uma aração e duas gradagens. A adubação básica, nos sulcos de

TABELA 1 - Temperatura (T) e umidade relativa (UR) do ar nos dias de aplicação do adubo foliar.

\begin{tabular}{|c|c|c|c|c|c|c|}
\hline & \multicolumn{6}{|c|}{ HORÁRIO DE LEITURA } \\
\hline & \multicolumn{2}{|c|}{$9 \mathrm{~h}$} & \multicolumn{2}{|c|}{$15 \mathrm{~h}$} & \multicolumn{2}{|c|}{$18 \mathrm{~h}$} \\
\hline & $\mathrm{T}\left({ }^{\circ} \mathrm{C}\right)$ & UR(\%) & $\mathrm{T}\left({ }^{\circ} \mathrm{C}\right)$ & UR(\%) & $\mathrm{T}\left({ }^{\circ} \mathrm{C}\right)$ & UR(\%) \\
\hline $\begin{array}{l}1^{\text {a }} \text { aplicação } \\
(19 / 07 / 96)\end{array}$ & 20,8 & 67,1 & 30 & 61,2 & 27,8 & 30,9 \\
\hline $\begin{array}{l}2^{\mathrm{a}} \text { aplicação } \\
(13 / 08 / 96)\end{array}$ & 23,6 & 74,7 & 35,2 & 41,6 & 32 & 50,5 \\
\hline $\begin{array}{l}3^{\mathrm{a}} \text { aplicação } \\
(27 / 08 / 96)\end{array}$ & 26,3 & 70,7 & 34,3 & 50,6 & 32 & 39,8 \\
\hline
\end{tabular}

Scientia Agricola, v.57, n.2, p.293-298, abr./jun. 2000 semeadura, foi de $200 \mathrm{~kg} \mathrm{ha}^{-1}$ da fórmula 04-30-10, realizada levando-se em consideração as características químicas do solo e as recomendações de Raij et al. (1985).

$O$ delineamento experimental utilizado foi 0 de blocos ao acaso em esquema fatorial $6 \times 3 \times 2$, com quatro repetições. Os tratamentos foram constituídos pela combinação de seis concentrações de uréia $(0,40,60,80$, 100 e $120 \mathrm{~g} \mathrm{~kg}^{-1}$ ) aplicadas via foliar em três horários (08h, $16 \mathrm{~h}$ e 20h), na presença ou ausência de adubação nitrogenada em cobertura (via solo). As parcelas foram constituídas por 6 linhas de $5 \mathrm{~m}$ de comprimento, considerando-se como área útil as 4 linhas centrais, desprezando-se 0,5 metro em ambas as extremidades de cada linha, sendo que em três linhas avaliaram-se a produção e em uma linha foram realizadas as amostragens de plantas.

A semeadura foi realizada mecanicamente em 24.06.1996, utilizando o cultivar IAC Carioca, com espaçamento entrelinhas de $0,5 \mathrm{~m}$ e 12 sementes viáveis por metro de sulco.

O fornecimento de nitrogênio via foliar por meio da utilização de diferentes concentrações de uréia, foi realizado com pulverizador costal, aplicando-se $200 \mathrm{~L} \mathrm{ha}^{-1}$ de solução, nas seguintes etapas de desenvolvimento das plantas, conforme descrição de Fernandez et al. (1992): $1^{a}$ aplicação (19/07/96) na fase vegetativa $V_{4}$ (emissão da $3^{\mathrm{a}}$ folha trifoliada), $2^{\mathrm{a}}$ aplicação (13/08/96) e $3^{\mathrm{a}}$ aplicação $(27 / 08 / 96)$ nas fases reprodutivas $R_{5}$ e $R_{7}$ (pré floração e formação de vagens), respectivamente. Nas parcelas com adubação em cobertura nitrogenada, o fornecimento de $\mathrm{N}$ foi realizado aos 32 dias após a emergência das plantas (dae), aplicando-se a dose de $40 \mathrm{~kg} \mathrm{ha}^{-1}$, conforme recomendação de Raij et al. (1985), utilizando-se uréia como fonte de $\mathrm{N}$. Após a aplicação de $\mathrm{N}$ em cobertura o ensaio foi irrigado aplicando-se uma lâmina d'água de 5 $\mathrm{mm}$, visando minimizar as perdas de $\mathrm{N}$ por volatilização. Os demais tratos culturais e fitossanitários foram os normalmente utilizados na cultura do feijão de inverno na região.

Foram anotados os seguintes dados: a) florescimento pleno: número de dias transcorridos entre a emergência e quando $50 \%$ das plantas das parcelas apresentavam pelo menos uma flor; b) peso da matéria seca de plantas: por ocasião do florescimento pleno coletaram-se 8 plantas de cada parcela e estas foram colocadas em estufa com circulação forçada de ar a 60$70^{\circ} \mathrm{C}$, até atingir peso constante; c) teor de $\mathrm{N}$ total nas folhas: foram coletadas todas as folhas de 5 plantas de cada parcela no florescimento pleno e estas foram colocadas em estufa com circulação forçada de ar a 60$70^{\circ} \mathrm{C}$, por 72 horas e em seguida foram moídas e submetidas a digestão sulfúrica, conforme metodologia de Sarruge \& Haag (1974); d) teor de umidade nas folhas: momentos antes da aplicação de $\mathrm{N}$ via foliar, foram coletadas 15 folhas por bloco, armazenadas em sacos plásticos previamente tarados, para posterior determinação do teor de umidade das mesmas; e) fitotoxicidade: quatro 
dias após as aplicações de $\mathrm{N}$ via foliar foi avaliado $\mathrm{o}$ sintoma visual de fitotoxicidade em cada parcela, através de um sistema de notas, que variava de 1 a 5 , onde a nota 1 correspondia a ausência de sintomas, a nota 2 a pouco sintoma, a nota 3 a sintomas moderados, a nota 4 a sintomas acentuados e a nota 5 à sintomas bastante acentuados; f) componentes de produção: coletaram-se 10 plantas de cada parcela, determinando-se o número médio de vagens/planta, número médio de grãos/planta, número médio de grãos/vagem, peso de 100 grãos e em duas fileiras da área útil foi determinado o rendimento de grãos.

Realizou-se a análise de variância, sendo as médias dos tratamentos que compunham o esquema fatorial $6 \times 3 \times 2$, comparadas pelo teste de Tukey a $5 \%$ de probabilidade.

\section{RESULTADOS E DISCUSSÃO}

Os resultados da avaliação da fitotoxicidade nas folhas em função da aplicação de $\mathrm{N}$ via foliar estão apresentados na TABELA 2. Observa-se que ocorreram sintomas de danos somente na aplicação realizada na fase $\mathrm{V}_{4}$, ou seja, por ocasião da emissão da terceira folha trifoliolada, onde o tratamento que apresentou maior valor para o sintoma (nota 3,75 - moderado a acentuado) foi o tratamento 11 (120 g kg de uréia às $16 \mathrm{~h}$ ) seguido pelos tratamentos 6 (120 g kg de uréia às $08 \mathrm{~h})$ e 10 (100 g kg ${ }^{1}$ de uréia às $16 \mathrm{~h}$ ) os quais receberam as notas 2,75 e 2,25 respectivamente. Os demais tratamentos apresentaram ausência ou leve sintoma de fitotoxicidade. Nas aplicações de uréia via foliar realizadas nas fases $R_{5}$ e $R_{7}$ (pré florescimento e formação de vagens, respectivamente) não foram detectados sintomas de fitotoxicidade nas folhas. Isso talvez possa ser explicado devido à maior área foliar das plantas por ocasião da segunda e terceira aplicação, considerando que foi utilizado o mesmo volume de calda (200 L ha ${ }^{-1}$ ) em todas as aplicações. Os resultados são concordantes aos de Boareto et al. (1985) que não observaram sinais de injúrias após 4 dias, em aplicações realizadas pela manhã ou à tarde. Os resultados obtidos mostraram que são importantes a concentração e o horário de aplicação; embora Neptune \& Muraoka (1978) e Boaretto et al. (1985) observaram que a uréia pode ser empregada até a concentração de $100 \mathrm{~g} \mathrm{~kg}^{-1}$, independentemente das condições ambientais e de até $200 \mathrm{~g} \mathrm{~kg}^{-1}$ em aplicação feitas no começo da manhã.

$O$ teor de umidade nas folhas, TABELA 3, não foi afetado pelos tratamentos em que se aplicou $\mathrm{N}$ via foliar, mostrando que, provavelmente, este fator não teve nenhum efeito sobre a ocorrência de fitotoxicidade observada por ocasião da primeira aplicação e que esta deve ter ocorrido em função da maior concentração do fertilizante e também porque nesta fase de desenvolvimento das plantas as mesmas apresentassem maior sensibilidade ao produto em concentrações mais elevadas.

Os valores obtidos na avaliação da matéria seca
TABELA 2 - Avaliação da fitotoxicidade realizada 4 dias após a aplicação de $\mathrm{N}$ via foliar (média de quatro repetições de quatro repetições)

\begin{tabular}{|c|c|}
\hline \multirow{2}{*}{ Tratamentos } & Avaliação de Fitotoxicidade* \\
\hline & $1^{\text {a }}$ Aplicação (3 folhas) \\
\hline 1- Tetemunha & 1,00 \\
\hline 2- $4 \%$ de uréia - $8 \mathrm{~h}$ & 1,25 \\
\hline 3- $6 \%$ de uréia - $8 h$ & 1,00 \\
\hline 4- $8 \%$ de uréia - $8 \mathrm{~h}$ & 1,75 \\
\hline 5- $10 \%$ de uréia - $8 \mathrm{~h}$ & 2,00 \\
\hline 6- $12 \%$ de uréia - $8 \mathrm{~h}$ & 2,75 \\
\hline $7-4 \%$ de uréia $-16 h$ & 1,00 \\
\hline $8-6 \%$ de uréia $-16 \mathrm{~h}$ & 1,00 \\
\hline $9-8 \%$ de uréia $-16 \mathrm{~h}$ & 1,75 \\
\hline $10-10 \%$ de uréia $-16 \mathrm{~h}$ & 2,25 \\
\hline $11-12 \%$ de uréia $-16 \mathrm{~h}$ & 3,75 \\
\hline 12- $4 \%$ de uréia - $20 \mathrm{~h}$ & 1,00 \\
\hline $13-6 \%$ de uréia - $20 \mathrm{~h}$ & 1,00 \\
\hline 14- $8 \%$ de uréia - $20 \mathrm{~h}$ & 1,00 \\
\hline $15-10 \%$ de uréia - $20 \mathrm{~h}$ & 1,00 \\
\hline $16-12 \%$ de uréia $-20 \mathrm{~h}$ & 1,00 \\
\hline
\end{tabular}

* Escala de notas (sitomas de fitotoxidez): 1- ausencia; 2- pouco; 3 moderado; 4- acentuado;5- bastante acentuado.

TABELA 3 - Avaliação do teor médio de água nas folhas, no momento da aplicação de $\mathrm{N}$ via foliar nas diferentes épocas e horários de aplicação.

\begin{tabular}{|c|c|c|c|}
\hline \multirow[t]{2}{*}{ Ho rário de Aplicação } & \multicolumn{3}{|c|}{ Época de aplicação } \\
\hline & $1^{\mathrm{a}}$ & $2^{a}$ & $3^{a}$ \\
\hline & \multicolumn{3}{|c|}{$\mathrm{g} \mathrm{kg}^{-1}$} \\
\hline $8 \mathrm{~h}$ & 890,8 & 871,0 & 840,4 \\
\hline $16 \mathrm{~h}$ & 880,5 & 860,0 & 820,2 \\
\hline $20 \mathrm{~h}$ & 880,7 & 860,5 & 820,2 \\
\hline
\end{tabular}

das plantas, teor de $\mathrm{N}$ total nas folhas, número de vagens e de grãos/planta estão apresentados na TABELA 4. Verificou-se que os tratamentos não provocaram diferenças significativas sobre estes parâmetros. Sá et al. (1982) e Arf et al. (1991) também observaram que a aplicação de nitrogênio no solo e/ou via foliar, não afetaram as características agronômicas avaliadas no feijoeiro, como número de vagens/planta e número de grãos/vagem. Entretanto Diniz et al. (1996) verificaram que o N aplicado em cobertura, aumentou o rendimento de grãos, número de vagens/planta, altura de plantas, peso de 100 grãos e stand final. Para Rosolem \& Boaretto (1987) as aplicações foliares de $\mathrm{N}$, até a época do florescimento podem provocar aumento no número de grãos/vagem e número de vagens/planta, assim como pequeno aumento no peso de 100 grãos, ao passo que adubações posteriores podem aumentar o peso de 100 grãos. Entretanto é importante mencionar que estes incrementos foram pequenos, e nem 
TABELA 4 - Valores médios obtidos da matéria seca de plantas, teor de N nas folhas, número de vagens/planta, e número de grãos/ planta na cultura do feijoeiro, cv. IAC Carioca em função da aplicação de N via solo e foliar em diferentes concentrações e horários de aplicação.

\begin{tabular}{|c|c|c|c|c|c|}
\hline \multicolumn{2}{|l|}{ Tratamentos } & \multirow{2}{*}{$\begin{array}{c}\text { Matéria seca de } \\
\text { plantas } \\
\text { (g por planta) }\end{array}$} & \multirow{2}{*}{$\begin{array}{c}\text { Teor de } N \text { nas } \\
\text { folhas } \\
\left(\mathrm{g} \mathrm{kg}^{-1}\right)\end{array}$} & \multirow[t]{2}{*}{$\begin{array}{c}n^{\circ} \text { de } \\
\text { vagens/planta }\end{array}$} & \multirow[t]{2}{*}{$\begin{array}{c}n^{\circ} \text { de } \\
\text { grãos/planta }\end{array}$} \\
\hline & & & & & \\
\hline \multirow{2}{*}{$\begin{array}{l}\text { Cobertura } \\
\text { via solo }\end{array}$} & $0 \mathrm{~kg} \mathrm{ha}^{-1}$ de $\mathrm{N}$ & 8,9 & 31,4 & 10,7 & 50,8 \\
\hline & $40 \mathrm{~kg} \mathrm{ha}^{-1}$ de $\mathrm{N}$ & 9,3 & 32,9 & 11,8 & 55,7 \\
\hline \multicolumn{6}{|c|}{ Adubação Foliar } \\
\hline & Testemunha & 8,1 & 31,5 & 11,4 & 55,7 \\
\hline & $40 \mathrm{~g} \mathrm{~kg}^{-1}$ de uréia & 9,2 & 32,1 & 11,4 & 54,5 \\
\hline & $60 \mathrm{~g} \mathrm{~kg}^{-1}$ de uréia & 8,9 & 31,8 & 11,0 & 50,5 \\
\hline \multirow[t]{3}{*}{ Doses } & $80 \mathrm{~g} \mathrm{~kg}^{-1}$ de uréia & 9,2 & 32,7 & 10,9 & 52,0 \\
\hline & $100 \mathrm{~g} \mathrm{~kg}^{-1}$ de uréia & 9,5 & 31,8 & 11,4 & 54,1 \\
\hline & $120 \mathrm{~g} \mathrm{~kg}^{-1}$ de uréia & 9,1 & 32,6 & 11,5 & 53,9 \\
\hline \multirow{3}{*}{$\begin{array}{l}\text { Horário } \\
\text { de aplicação }\end{array}$} & $8 \mathrm{~h}$ & 9,1 & 31,7 & 11,1 & 52,5 \\
\hline & $16 \mathrm{~h}$ & 9,1 & 31,9 & 11,3 & 53,5 \\
\hline & $20 \mathrm{~h}$ & 8,7 & 33,0 & 11,4 & 54,4 \\
\hline CV (\%) & & 30,49 & 9,04 & 27,23 & 29,11 \\
\hline
\end{tabular}

Para as características avaliadas, todos os fatores assim como suas interações não apresentaram efeito significativo pelo teste $F$, a análise de regressão para doses também não se mostrou significativa para essas características.

sempre se conseguiu significância estatística das diferenças observadas experimentalmente.

Em relação aos teores de nitrogênio nas folhas, nota-se que todos os resultados obtidos estão acima do nível crítico de nitrogênio para a cultura, que é de $30 \mathrm{~g} \mathrm{~kg}^{-1}$ (Ambrosano et al., 1996a). Valores semelhantes à estes foram observados por Bulisani et al. (1973) onde os teores de nitrogênio nas folhas de feijoeiro se situaram ao redor de $33,0 \mathrm{~g} \mathrm{~kg}^{-1}$, enquanto que Araújo et al. (1987) observaram teores acima de $47,0 \mathrm{~g} \mathrm{~kg}^{-1}$ muito embora neste trabalho a aplicação do nitrogênio tenha sido via solo. Outro fator importante é que tanto Bulisani et al. (1973) como Araújo et al. (1987) e também no presente trabalho os teores foliares de $\mathrm{N}$ na testemunha se mostraram superiores ao nível crítico. Por outro lado Endo et al. (1988) observaram maiores teores de $\mathrm{N}$ nas folhas com a aplicação do nutriente em cobertura quando comparado com a testemunha. Acredita-se que os altos teores de $\mathrm{N}$ nas folhas das plantas no tratamento testemunha, se deva ao fato de que provavelmente tenha ocorrido uma melhoria do solo ocasionada por cultivos anteriores, que criaram condições favoráveis para atendimento das necessidades de $\mathrm{N}$ da cultura, ou então, porque a população microbiana natural do solo tenha sido eficiente na fixação do $\mathrm{N}$ atmosférico.

Não foram também observadas diferenças significativas entre os valores médios das características agronômicas número de grãos/vagem e peso de 100 grãos, os quais estão apresentados na TABELA 5.

Diniz et al. (1996) observaram aumento no peso de 100 grãos com a aplicação de $30 \mathrm{~kg} \mathrm{ha}^{-1}$ de $\mathrm{N}$ em relação à testemunha, já Araújo et al. (1987) verificaram resultados conflitantes com relação à este parâmetro onde as doses de 30 e $90 \mathrm{~kg} \mathrm{ha}^{-1}$ de $\mathrm{N}$ proporcionaram peso de 100 grãos significativamente superior aos obtidos com a dose de $60 \mathrm{~kg} \mathrm{ha}^{-1}$ de $\mathrm{N}$, porém não diferiram significativamente da testemunha. Entretanto, resultados semelhantes, aos deste trabalho, foram obtidos por Richart et al. (1998), que também não observaram aumentos significativos no peso de 100 grãos e no número de grãos/vagem, com a aplicação de $30 \mathrm{~kg} \mathrm{ha}^{-1}$ de $\mathrm{N} \mathrm{em}$ cobertura.

Com relação a produção de grãos (TABELA 4) a aplicação em cobertura de $\mathrm{N}$, via solo, proporcionou produção significativamente superior em relação à testemunha. Cunha et al. (1980) observaram aumento significativo na produção com a aplicação de $\mathrm{N}$, verificaram também que o comportamento relativo dos níveis de nitrogênio aplicado variaram de ano para ano. Ambrosano et al. (1996b) verificaram que a aplicação de nitrogênio no feijoeiro irrigado proporcionou aumento na produtividade da cultura, sendo que em solo de fertilidade mais baixa a cultura respondeu ao parcelamento do nitrogênio. Ressaltaram ainda que a combinação de nitrogênio no solo e foliar é mais efetiva do que a aplicação do nutriente apenas por via foliar. Urben Filho et al. (1980), Araya et al. (1981) e Diniz et al. (1996) também observaram resultados positivos com a aplicação de $\mathrm{N}$ via solo. Richart et al. (1998), similar as observações de Ambrosano et al. (1996b) também verificaram aumento na produção do feijoeiro em função da aplicação de $\mathrm{N}$ em cobertura via solo e ou foliar. Já Rosolem et al. (1983) e Balducci Junior et al. (1984), não encontraram efeito significativo entre a adubação nitrogenada em cobertura via solo e ou foliar e 
TABELA 5 - Valores médios de número de grãos/vagem, peso de 100 grãos e produção do feijoeiro cultivar IAC Carioca em função da aplicação de $\mathrm{N}$ via solo e foliar em diferentes concentrações e horários de aplicação.

\begin{tabular}{|c|c|c|c|c|}
\hline Tratamentos & & $\mathrm{n}^{\circ}$ de grãos/vagem & Peso de 100 grãos & Produção \\
\hline & & & (g) & $\left(\mathrm{kg} \mathrm{ha}^{-1}\right)$ \\
\hline \multirow{2}{*}{ Cobertura solo } & $0 \mathrm{~kg} \mathrm{ha}^{-1}$ de $\mathrm{N}$ & 4,8 & 24,1 & $1944 b$ \\
\hline & $40 \mathrm{~kg} \mathrm{ha}^{-1}$ de $\mathrm{N}$ & 4,8 & 24,5 & $2088 \mathrm{a}$ \\
\hline \multicolumn{5}{|l|}{ Adubação Foliar } \\
\hline & Testemunha & 4,9 & 24,2 & 2073 \\
\hline & $40 \mathrm{~g} \mathrm{~kg}^{-1}$ de uréia & 4,9 & 24,5 & 1965 \\
\hline & $60 \mathrm{~g} \mathrm{~kg}^{-1}$ de uréia & 4,6 & 24,5 & 2118 \\
\hline \multirow[t]{3}{*}{ Doses } & $80 \mathrm{~g} \mathrm{~kg}^{-1}$ de uréia & 4,8 & 23,8 & 2018 \\
\hline & $100 \mathrm{~g} \mathrm{~kg}^{-1}$ de uréia & 4,7 & 24,1 & 1961 \\
\hline & $120 \mathrm{~g} \mathrm{~kg}^{-1}$ de uréia & 4,7 & 24,3 & 1963 \\
\hline \multirow{3}{*}{$\begin{array}{l}\text { Horário } \\
\text { de aplicação }\end{array}$} & $8 \mathrm{~h}$ & 4,8 & 24,1 & 1999 \\
\hline & $16 \mathrm{~h}$ & 4,8 & 24,1 & 2004 \\
\hline & $20 \mathrm{~h}$ & 4,7 & 24,5 & 2046 \\
\hline Teste F & Cobertura - solo & $0,0986 \mathrm{~ns}$ & $3,2864 \mathrm{~ns}$ & $4,5875^{*}$ \\
\hline CV (\%) & & 11,69 & 7,35 & 19,99 \\
\hline DMS (Tukey 5\%) & Cobertura - solo & & & 132,9 \\
\hline
\end{tabular}

Letras comuns na mesma coluna, não diferem a $5 \%$ pelo teste de Tukey, em cada fator analisado.

ns = não significativo pelo teste $\mathrm{F}$ a $5 \%$.

* = significativo pelo teste $\mathrm{F}$ a $5 \%$.

Exceto para produção de grãos, todos os fatores assim como suas interações não apresentaram efeito significativo pelo teste $F$, e a análise de regressão para doses também não se mostrou significativa para essas características, inclusive para produção de grãos.

a produção de grãos, muito embora Rosolem et al. (1983) tenham observado incrementos de 22 a $26 \%$ na produção com a aplicação de nitrogênio em relação à testemunha.

Nota-se que os resultados encontrados na literatura a respeito da adubação nitrogenada, são controvertidos, e como ressaltou Vieira (1998) no estado de Minas Gerais, de um total de 71 ensaios de campo, conduzidos em 30 municípios, em 43 desses, ou seja em $61 \%$ dos ensaios, houve resposta positiva à aplicação do N. Situação semelhante também pode ser observada no trabalho de Ambrosano et al. (1996b), que verificaram respostas diferentes para a aplicação de $\mathrm{N}$ de um ano para outro no município de Votuporanga-SP. Essas divergências na resposta do feijoeiro à adubação nitrogenada, podem estar no fato de a planta do feijoeiro apresentar ciclo curto (90 a 100 dias) e sistema radicular pouco desenvolvido, estando sujeito a queda na produtividade em função de qualquer tipo e nível de "stress" (Rosolem \& Boaretto, 1987). Além do que, cultivares diferentes, condições de clima e de solo ditam a resposta da cultura a aplicação do nutriente. E ainda conforme foi ressaltado por Rosolem (1996) as condições de respostas à aplicação de nitrogênio estão sujeitas a situação do solo do local de semeadura (cultura anterior, teor de matéria orgânica, compactação do solo, textura do solo e irrigação), de forma que o histórico da área onde vai se implantar a cultura é fundamental para se obter resposta ao nutriente.

\section{CONCLUSÕES}

- Fornecimento de nitrogênio via solo, provocou um pequeno aumento na produtividade do feijoeiro de inverno.

- A adubação nitrogenada via foliar em diferentes concentrações e horários de aplicação, não afetou as características agronômicas e a produtividade do feijoeiro.

- É importante a época de aplicação e a concentração da uréia via foliar, tendo em vista que pode ocorrer fitotoxicidade.

- A combinação de $\mathrm{N}$ no solo e foliar, não se mostrou efetiva.

\section{REFERÊNCIAS BIBLIOGRÁFICAS}

AMBROSANO, E.J.; TANAKA, R.T.; MASCARENHAS, H.A.A.; RAIJ. B. van; QUAGGIO, J.A.; CANTARELLA, H. Leguminosas e oleaginosas. In: RAIJ, B. van; CANTARELLA, H.; QUAGGIO, J.A.; FURLANI A.M.C. (Ed.) Recomendações de adubação e calagem para o Estado de São Paulo. 2.ed. Campinas: Instituto Agronômico/Fundação IAC, 1996a. cap.19, p.187-199.

AMBROSANO, E.J.; WUTKE, E.B.; AMBROSANO, G.M.B.; BULISANI, E.A.; BORTOLETTO, N.; MARTINS, A.L.M.; PEREIRA, J.C.V.N.A.; DE SORDI, G. Efeito do nitrogênio no cultivo de feijão irrigado no inverno. Scientia Agricola, v.53, p.338-342, 1996b.

ARAÚJO, G.A.A.; FONTES, L.A.N.; AMARAL, F.A.L.; CONDÉ, A.R. Influência do molibdênio e do nitrogênio sobre duas variedades de feijão (Phaseolus vulgaris L.). Revista Ceres, n.34, p.333-339, 1987 
ARAYA, V.R.; VIEIRA, C.; MONTEIRO, A.A.T.; CARDOSO, A.A.; BRUNE, W. Adubação nitrogenada da cultura do feijão (Phaseolus vulgaris L.), na Zona da Mata de Minas Gerais. Revista Ceres, v.28, p.134-149, 1981.

ARF, O.; FORNASIERI FILHO, D.; MALHEIROS, E.B.; SAITO, S.M.T. Efeito da inoculação e adubação nitrogenada em feijoeiro (Phaseolus vulgaris L.) cultivar Carioca 80. Científica, v.19, p.29-38, 1991.

BALDUCCI JUNIOR, J.J.; ROSOLEM, C.; MACHADO, J.R. Adubação foliar do feijoeiro (Phaseolus vulgaris L.): III efeitos de NP e NPK. Revista da Agricultura, v.59, p.221-228, 1984.

BOARETTO, A.D.; DAGHLIAN, C.; MURAOKA, T.; CRUZ, A.P. Adubação do feijoeiro: fontes de nitrogênio, concentração da solução e horários de aplicação. Revista de Agricultura, v.60, p.117-123, 1985.

BULISANI, E.A.; ALMEIDA, L.A.D.; DEMATTÊ, J.D. Observações preliminares sobre adubação foliar em feijoeiro (Phaseolus vulgaris L.) I. Bragantia, v.32, p.XIII-XVII, 1973.

CUNHA, J.M.; GUAZZELLI, R.J.; DALL'ACQUA, F.M.; FERNANDES, D.C. Níveis de nitrogênio, na cultura do feijão. Pesquisa Agropecuária Brasileira, v.15, p.47-52, 1980.

DINIZ, A.R.; ANDRADE, M.J.B.; CARVALHO, J.G.; LIMA, S.F.; LUNKES, J.A. Resposta da cultura do feijão (Phaseolus vulgaris L.) à aplicação de nitrogênio (cobertura e semeadura) e de molibidênio foliar. In: REUNIÃO NACIONAL DE PESQUISA DE FEIJÃO, 5., Goiânia, 1996. Anais. Goiânia: EMBRAPA, CNPAF, 1996. p.73-75.

DUQUE, F.F.; NEVES, M.C.P.; FRANCO, A.A.; VICTORIA, R.L.; BODDEY, R.M. The response of field grown Phaseolus vulgaris $\mathrm{L}$. to Rhizobium inoculation and qualitication of $\mathrm{N}_{2}$ fixation using ${ }^{15} \mathrm{~N}$. Plant and Soil, v.88, p.333-343, 1985.

ENDO, R.M.; FORANASIERI FILHO, D.; MALHEIROS, E.B.; FORNASIERI, J.L. Efeito de inoculantes, nitrogênio e micronutrientes sobre os componentes produtivos na cultura do feijoeiro de inverno. Científica, v.16, p.141-150, 1988.

FERNANDEZ, F.; GEPTS, P.; LÓPEZ, M. Etapas do desenvolvimento da planta de feijão. In: EMPRESA DE PESQUISA AGROPECUÁRIA E DIFUSÃO DE TECNOLOGIA DE SANTA CATARINA. A cultura do feijão em Santa Catarina. Florianópolis: EMPASC, 1992. p.53-74.

FRANCO, A.A. Nutricional restraints for tropical grain legume symbiosis. In: VICENT, J.M.K.; WHITNEY, J. (Ed.). Exploiting the legume-Rhizobium in tropical agriculture. Hawai: University of Hawai, 1977. p.237-252.

GAMBOA, J.; PAREZ, G.; BLASCO, M. Un modelo para descobrir processos de retencion y lixiviacion em suelos. Turrialba, v.21, p.312-316, 1971.

NEPTUNE, A.M.L.; MURAOKA, T. Aplicação de uréia ${ }^{15} \mathrm{~N}$ em feijoeiro (Phaseolus vulgaris L.) cultivar Carioca. Revista Brasileira de Ciência do Solo, v.2, p.51-55, 1978.

OSINAME, O.; VAN GINJ, H.; ULEX, P.L.G. Effect nitrifications inhibitions of the fate and efficiency of nitrogenoms fertilizers under simulated homid tropical condutions. Tropical Agriculture, v.60, p.211-217, 1983.
RAIJ, B. van; QUAGGIO, J.A. Métodos de análise de solo para fins de fertilidade. Campinas: Instituto Agronômico, 1983. 31p. (Boletim Técnico, 81).

RAIJ, B. van.; SILVA, N.M.; BATAGLIA, O.C.; QUAGGIO, J.A.; HIROCE, R.; CANTARELLA, H.; BELLINAZZI JÚNIOR, R.; DECHEN, A.R.; TRANI, P.E. Recomendações de adubação e calagem para o estado de São Paulo. Campinas: Instituto Agronômico, 1985. 107p. (Boletim Técnico, 100).

RICHART, A.; PESSOA, A.C.S.; LUCHESE, E.B.; CAVALLET, L.E.; KUHN, O.J. Produtividade do feijoeiro "FT Nobre" em resposta ao manejo da adubação nitrogenada e à adubação foliar com molibidênio. In: REUNIÃO BRASILEIRA FERTILIDADE DO SOLO E NUTRIÇÃO DE PLANTAS, 23.; REUNIÃO BRASILEIRA SOBRE MICORRIZAS, 7.; SIMPÓSIO BRASILEIRO DE MICROBIOLOGIA DO SOLO, 5.; REUNIÃO BRASILEIRA DE BIOLOGIA DO SOLO, 2., Caxambu, 1998. Resumos. Caxambu: Universidade Federal de Lavras, 1998. p.478.

ROSOLEM, C.A. Nutrição e adubação do feijoeiro. Piracicaba: POTAFOS, 1987. 93p.

ROSOLEM, C.A. Calagem e adubação mineral. In: ARAÚJO, R.S.; RAVA, C.A.; STONE, L.F.; ZIMMERMANN, M.J.O. (Coord.) Cultura do feijoeiro comum no Brasil. Piracicaba: POTAFOS, 1996. cap.11, p.353-390.

ROSOLEM, C.A.; MACHADO, J.R.; KANTACK, R.A.D. Adubação foliar do feijoeiro. VI Efeitos de doses e épocas de aplicação de NPKS. Revista de Agricultura, v.58, p.305-314, 1983.

ROSOLEM, C.A.; BOARETTO, A.E. Adubação foliar do feijoeiro. In: SIMPÓSIO BRASILEIRO DE ADUBAÇÃO FOLIAR, 2., Botucatu, 1987. Anais. Campinas: Fundação Cargill, 1987. p.449-512.

ROSOLEM, C.A.; BOARETTO, A.E. Avaliação do estado nutricional das plantas cultivadas. In: BOARETTO, A.E.; ROSOLEM, C.A. (Ed.). Adubação foliar. Campinas: Fundação Cargill, 1989. p.117-144.

SÁ, M.E.; BUZETTI, S.; CONSTANT, E.A.; FRIZZONE, J.A.; SANTOS, P.C. Efeito da adubação nitrogenada na cultura do feijoeiro cultivar Carioca, cultivada em um solo sob vegetação de cerrado. In: REUNIÃO NACIONAL DE PESQUISA DE FEIJÃO, 1., Goiânia, 1982. Anais. Goiânia: EMBRAPA, CNPAF, 1982. p.161.

SARRUGE, J.R.; HAAG, H.P. Análises químicas em plantas. Piracicaba: ESALQ, Departamento de Química, 1974. 56p.

URBEN FILHO, G.; CARDOSO, A.A.; VIEIRA, C.; FONTES, L. A.N.; THIÉBAUT, J.T.L. Doses e modo de aplicação do adubo nitrogenado na cultura do feijão (Phaseolus vulgaris L.) Revista Ceres, v.27, p.302-312, 1980.

VIEIRA, C. Adubação mineral e calagem. In: VIEIRA, C.; PAULA JUNIOR, T.J.; BORÉM, A. (Ed). Feijão: aspectos gerais e cultura no Estado de Minas Gerais. Viçosa: UFV, 1998. p.123-152.

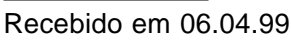

